\title{
Expression of the CS- and US-Pre-Exposure Effects in the Conditioned Taste Aversion Paradigm and Their Abolition Following Systemic Amphetamine Treatment in C57BL6/J Mice
}

\author{
Urs Meyer', De Li Tilly Chang', Joram Feldon' and Benjamin K Yee*,' \\ 'Laboratory of Behavioural Neurobiology, Swiss Federal Institute of Technology Zurich, Schwerzenbach, Switzerland
}

\begin{abstract}
In classical conditioning, pre-exposures to either the to-be-conditioned stimulus (CS) or unconditioned stimulus (US) can retard subsequent conditioning between the CS and US. The present experiment evaluated the expression of these two pre-exposure effects in mice of the C57BL6/J strain, one of the most common background strains for genetically altered mice. We tested whether their expression would be disrupted by amphetamine treatment $(2.5 \mathrm{mg} / \mathrm{kg}$, i.p. $)$ in a conditioned taste aversion paradigm with sucrose as the CS and lithium chloride-induced gastric malaise as the US. We found that one pre-exposure (PE) to either the CS or the US reduced aversion to sucrose solution in the controls following conditioning, but no such tendency was evident in the amphetamine-treated mice. The present study represents the first report of amphetamine-induced disruption of the CS-PE effect (ie latent inhibition) in mice, and the first attempt to compare it directly with the US-PE effect in any species. It extended previous reports in rats and humans, suggesting that the sensitivity of latent inhibition to amphetamine is largely comparable across species, thereby lending credence to the use of the latent inhibition effect as a behavioral assay for psychotic-like phenotype in transgenic mice. The parallel observation in the US-PE effect further indicates that its expression, at least in the present conditioned taste aversion paradigm, may also be under similar influence of the dopaminergic system.

Neuropsychopharmacology (2004) 29, 2 I40-2 I 48. advance online publication, 7 July 2004; doi: I 0. I038/sj.npp. 1300522
\end{abstract}

Keywords: amphetamine; associative learning; dopamine; latent inhibition; schizophrenia; US pre-exposure

\section{INTRODUCTION}

Associative learning is known to be influenced by the associative history of the stimuli, including the contextual cues that featured in the conditioning episode (Rescorla and Wagner, 1972; Kruschke, 2001). Prior pre-exposure to either the to-be-conditioned stimulus (CS) or unconditioned stimulus (US) can impede the development and/or expression of the conditioned response (CR) following subsequent pairing between the CS and the US. The reduction in the vigor of the $\mathrm{CR}$ observed following nonreinforced CS preexposure is referred to as latent inhibition (LI; Lubow and Moore, 1959), and that following US pre-exposure is referred to as the US pre-exposure effect (USPEE; Randich and LoLordo, 1979). Both phenomena can be demonstrated

\footnotetext{
* Correspondence: BK Yee, Laboratory of Behavioural Neurobiology, Swiss Federal Institute of Technology Zurich, Schorenstrasse 16, Schwerzenbach 8603, Switzerland, Tel: + 4l I 655 7417, Fax: +4I I 655 7203, E-mail: benjamin.yee@behav.biol.ethz.ch

Received 14 April 2004; revised 7 June 2004; accepted 9 June 2004 Online publication: 10 June 2004 at http://www.acnp.org/citations/ Npp06 100404174/default.pdf
}

in numerous species, including human and rodent, and across a variety of associative conditioning procedures (Lubow, 1989; Cannon et al, 1975; Batson and Best, 1979; Baker et al, 1981).

LI is commonly considered to index the ability to ignore stimuli that historically predict no significant consequences. It has been suggested that LI stems from the development of selective attention away from the pre-exposed stimulus, thus diminishes the perceived salience of the CS during conditioning (Mackintosh, 1975a; Lubow et al, 1981; Lubow, 1989). LI has also been attributed to the acquisition of an association between the to-be-conditioned CS with the absence of a significant consequence during pre-exposure, which later interferes with either the subsequent expression (Gray et al, 1991, 1995; Weiner, 1990, 2003) or retrieval (Bouton, 1993; Kraemer and Spear, 1992) of the CS-US association.

Several theoretical accounts of the USPEE can be readily identified in the literature (reviewed in Riley and Simpson, 2001). First, the USPEE can be characterized as a form of Kamin blocking mediated by contextual cues (Kamin, 1969). According to one interpretation, the formation of 
context-US association developed as a result of US preexposures impedes the subsequent generation of the $C R$ following pairings of the CS and US taken place in the same context. As an added element to the existing context, the CS is treated as redundant in predicting the occurrence of the US and therefore the animals learn not to initiate a CR (Mackintosh, 1975b; Mackintosh and Turner, 1971). Second, prior experience of the US can reduce the salience or surprise of the US such that subsequent CS-US association would precede more slowly (Domjan and Best, 1980). Third, US pre-exposures are expected to reduce the maximal associative strength commanded by the US due to the development of tolerance or habituation (Batson and Best, 1979; De Brugada et al, 2003a). These different views are not mutually exclusive, and they can all be incorporated within the classical Rescorla-Wagner model (Rescorla and Wagner, 1972). The question remains as to their relative contributions within a given conditioning paradigm.

The neural substrate of LI, and in particular its psychopharmacology, has been intensively studied in the rodents (as reviewed by Weiner, 1990, 2003; Moser et al, 2000) since the initial observation that LI can be disrupted by the indirect dopamine agonist, amphetamine (Solomon and Staton, 1982; Weiner et al, 1984, 1988). The sensitivity of the USPEE to similar dopaminergic manipulation has never been explored. Given that amphetamine has also been shown to attenuate Kamin blocking (Crider et al, 1982; Ohad et al, 1987; Jones et al, 1997; O'Tuathaigh et al, 2003), it would be expected to disrupt the USPEE to the extent that the USPEE can be attributed to blocking by context (Willner, 1978; Batson and Best, 1979; Cole et al, 1996).

The impetus of the present study was to examine whether the CS- and USPEE would be equally affected by systemic amphetamine treatment in the mouse. The efficacy of amphetamine to disrupt LI has been shown in rats as well as in humans (Solomon and Staton, 1982; Weiner et al, 1988; Gray et al, 1992; Thornton et al, 1996), which parallels reports of LI disruption in schizophrenia patients as well as schizoptypal individuals (Baruch et al, 1988; NS Gray et al, 1995; Escobar et al, 2002). This has led to the application of the LI paradigm to assess schizophrenia-related psychopathology in animals, including its recent application to genetically modified mice (Gainetdinov et al, 2001; Kilts, 2001; Miyakawa et al, 2003). With the rapidly emerging understanding of the genetic contribution to behavior and cognition, the murine species is being continually integrated into contemporary animal models of neuropsychiatric disorders (Tarantino and Bucan, 2000). Yet, the sensitivity of murine LI to amphetamine still awaits validation, and the present experiment would fill this lacuna in the literature. This would be of particular relevance to the continual reliance on the murine species in animal modelling of schizophrenia.

A conditioned taste aversion (CTA) paradigm was employed in the present study, in which sucrose taste served as the CS, and gastric malaise induced by systemic lithium chloride ( $\mathrm{LiCl}$ ) acted as the US. In the rat, the expression of LI in the CTA paradigm has been shown to be sensitive to amphetamine treatment when the drug was administered prior to both pre-exposure and conditioning (Russig et al, 2003). Here, we aimed to directly compare the effect of amphetamine on the expression of the CS- and
USPEE by reference to a single non-pre-exposed control group (NPE) using a factorial between-subjects design.

\section{MATERIALS AND METHODS}

\section{Subjects}

Naïve male adult mice of the C57BL6/J strain, weighing 25$32 \mathrm{~g}$, were obtained from our in-house specific-pathogenfree (SPF) breeding facility. Littermates of three to five mice were kept in groups in Macrolon Type-III cages, and maintained under ad libitum food (Kliba 3430, Klibamühlen, Kaiseraugst, Switzerland) and water. They were left undisturbed for 5 days for days for acclimatization to the new animal holding room, which was a temperature- and humidity-controlled $\left(21 \pm 1^{\circ} \mathrm{C}, 55 \pm 5 \%\right)$ vivarium under a reversed light-dark cycle (lights off: 0800-2000). They were then switched to single caging in the same type of cages, in which behavioral testing would subsequently take place (see Procedures below).

The animals were allocated to one of six conditions according to a $3 \times 2$ (Stimulus Pre-exposure $\times$ Drug) factorial design. The six conditions were: Non-pre-exposed [NPE]/Saline [Sal] $(n=10)$, CS-pre-exposed [CS-PE]/Sal $(n=11)$, US-pre-exposed [US-PE]/Sal $(n=11), \quad \mathrm{NPE} /$ Amphetamine [Amph] $(n=12), \mathrm{CS}-\mathrm{PE} / \mathrm{Amph} \quad(n=11)$, and US-PE/Amph $(n=11)$. As far as possible, littermates from each litter were always assigned to different experimental conditions in order to minimize the potential confound resulting from litter effects (Zorrilla, 1997).

All behavioral manipulations were carried out in the dark phase of the cycle. The procedures described in the present study had been previously approved by the Swiss Cantonal Veterinary Office, and are in agreement with the Principles of Laboratory Animal Care (NIH publication No. 86-23, revised 1985).

\section{Preparation of D-Amphetamine and Lithium Chloride}

All injected substances were obtained from Sigma-Aldrich (Switzerland), freshly prepared on the required days in solution form, and administered via the intraperitoneal (i.p.) route.

D-Amphetamine sulfate was dissolved in a $0.9 \% \mathrm{NaCl}$ solution to obtain the desired dosage $(2.5 \mathrm{mg} / \mathrm{kg}$, calculated as the salt). Vehicle-treated control animals received $0.9 \%$ $\mathrm{NaCl}$ solution. The volume of injection for amphetamine and saline was $5 \mathrm{ml} / \mathrm{kg}$, and the injections were made $30 \mathrm{~min}$ before the pre-exposure and conditioning session.

Lithium chloride ( $\mathrm{LiCl}$ ) was dissolved in $0.9 \% \mathrm{NaCl}$ to achieve a concentration of $0.25 \mathrm{M}$. It was injected in a volume of $2 \% \mathrm{v} / \mathrm{w}$ body weight. $\mathrm{LiCl}$ was administered to animals in the US-PE groups immediately after the preexposure (to water) session and after the conditioning session (conducted $24 \mathrm{~h}$ later). The remaining animals (NPE and CS-PE subjects) received an injection of saline vehicle immediately after the pre-exposure session, and an injection of $\mathrm{LiCl}$ immediately following the conditioning session.

\section{Apparatus}

The animals were kept singly in Macrolon type III cages throughout the experiment. The drinking tubes were made 
from $15 \mathrm{ml}$ polypropylene test tubes (Cellstar ${ }^{\circledR}$, Greiner Bio-One, Frickenhausen, Germany) and equipped with an air-tight screwed top. An opening of $2.5 \mathrm{~mm}$ in diameter was made at the end of the tubes, thus allowing the animal access to the liquid contained therein without leakage. Two acrylic rings $(20 \mathrm{~mm}$ in inner diameter) were mounted in between the metal grids of the cage top to allow the efficient placement and removal of the drinking tubes, which could be fitted smoothly into the lumen of the rings, and remained in place with the tube cap resting on top of the ring. When the two drinking tubes were in place, a distance of $40 \mathrm{~mm}$ separated the openings of the two drinking tubes, at a level of approximately $50 \mathrm{~mm}$ above the cage floor that was covered with sawdust. The placement was such that the animals could easily switch drinking from one tube to the other.

Liquid consumption from a given drinking tube was calculated by taking the difference in its weight before and after a drinking session.

\section{Procedures}

On the day after the animals were switched to single caging, they were gradually introduced to a water deprivation regime over a 5 -day period to achieve $23 \mathrm{~h}$ water deprivation on the fifth day. On all subsequent days, the animals were allowed daily access to fluid in two 30-min periods, separated by a 4-h interval. During the drinking period, the animals had free access to two tubes, and the second period always consisted of water only. All animals received two injections on the PE and conditioning day, and not on the test day.

The experimental procedures consisted of four stages as described below and illustrated in Figure 1.

- Baseline. From days 1 to 4 , the animals were allowed access to water in both drinking periods on each day. This served to stabilize the volume of daily water intake. The allocation of subjects to each of the six experimental conditions was also counterbalanced according to the animals' baseline performance.

- Pre-exposure. On day 5, animals allocated to the NPE and US-PE groups had access to water as described above. Animals in the CS-PE groups were given access to $10 \%$ sucrose solution in both drinking tubes during the first drinking period.

The animals were injected with amphetamine or saline, $30 \mathrm{~min}$ prior to the first drinking period. At the end of the first drinking period, animals in the US-PE condition received an injection of $\mathrm{LiCl}$ whereas the other animals received an injection of saline.

- Conditioning. On day 6, all animals were given access to $10 \%$ sucrose solution for $30 \mathrm{~min}$ in the first drinking

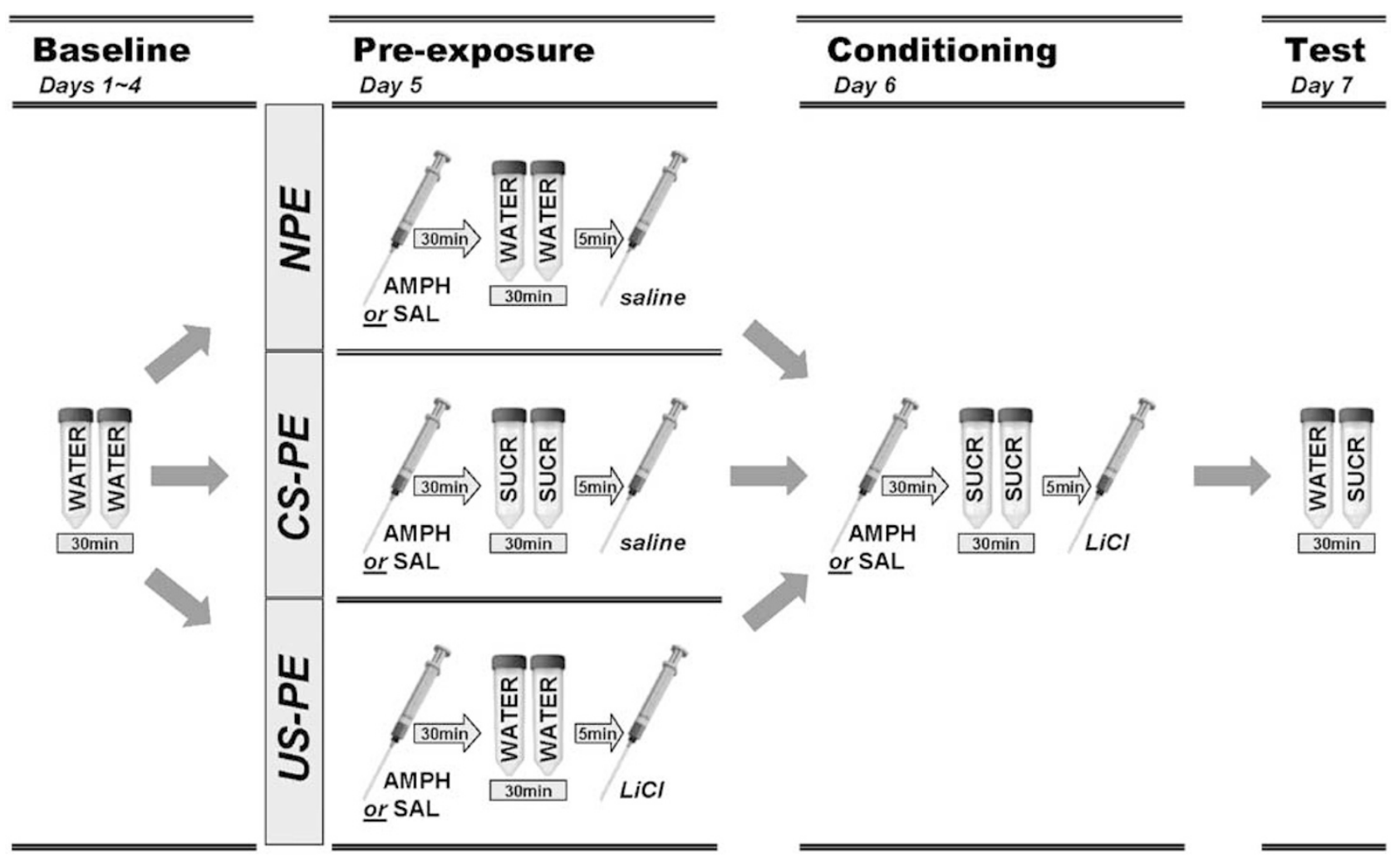

Figure I Diagrammatic representation of the experimental design. Baseline water consumption was measured for all animals during days I-4; subjects were then allocated to the three pre-exposure conditions (NPE, CS-PE, US-PE), and further subdivided into the two (Amph vs Sal) drug conditions within each pre-exposure condition. The animals' baseline performance (days I-4) was counterbalanced across the six experimental groups (NPE/Sal, NPE/Amph, CS-PE/Sal, CS-PE/Amph, US-PE/Sal, US-PE/Amph). Here, the procedural manipulations and their timing and sequence at the first drinking period throughout the experiment are illustrated. Four hours later on each day, all animals received water for an additional 30 min. For a full description of the methods, refer to the Procedures section. 
period, followed by a $\mathrm{LiCl}$ injection $5 \mathrm{~min}$ later. At $30 \mathrm{~min}$ prior to the first drinking period, the animals were either pretreated with Sal or Amph.

- Test. On day 7, conditioned aversion to the sucrose taste was measured in a two-choice test with one drinking tube filled with $10 \%$ sucrose solution, and the other water.

\section{Statistical Analysis}

The data were analyzed using parametric analysis of variance (ANOVA), and supplemented with additional analyses of covariance (ANCOVA). These were carried out by the statistical software, SPSS for Windows (Release 11.0.1, 2001), implemented on a PC running the MSWindow XP operating system.

Data from the pre-exposure conditioning, and test sessions of the experiment were analyzed separately. Baseline data were not subjected to analysis because these were counterbalanced among groups. No data were obtained on the amounts of water consumption in the second drinking period across all phases of the experiment. Significant main effects and interactions were further investigated by Fisher's LSD post-hoc comparisons to ascertain the specific form of the statistical effects emerged.

\section{RESULTS}

\section{Pre-Exposure Session}

The amount of liquid consumption (sucrose for CS-PE subjects, and water for NPE and US-PE subjects) was subjected to a $3 \times 2$ (Stimulus pre-exposure $\times$ Drug) randomized block ANOVA. Amphetamine treatment significantly reduced liquid consumption across all three stimulus preexposure conditions (Figure 2a). Across the three stimulus pre-exposure conditions, no difference was detected in the saline-treated controls. Among the amphetamine-treated subjects, the CS-PE/Amph showed the lowest amount of liquid (sucrose) consumption.

These impressions were supported by the main effect of drug $(\mathrm{F}=251.16, \mathrm{df}=1,60, P<0.001)$, of pre-exposure $(\mathrm{F}=7.79, \quad \mathrm{df}=2,60, \quad P=0.001), \quad$ and their interaction $(\mathrm{F}=3.92, \mathrm{df}=2,60, P<0.05)$. Post-hoc comparisons indicated that the interaction stemmed from a lack of a preexposure effect in the saline-treated mice and the presence of a pre-exposure effect in the amphetamine-treated animals (see Figure 2a). The latter consisted of a significant reduction of liquid (sucrose) consumption in the Amph/CS$\mathrm{PE}$ subjects, compared to the amount of liquid (water) intake by the Amph/NPE and Amph/US-PE subjects $(P$ 's $<0.05)$, which did not differ from each other.

\section{Conditioning Session}

The amount of sucrose intake on the conditioning session was subjected to an ANOVA as described before. Again, amphetamine led to a pronounced reduction in liquid consumption, which was evident in all pre-exposure conditions (Figure 2b). Unlike the pattern of results obtained in the pre-exposure phase, liquid consumption was affected by stimulus pre-exposure history in the salinetreated controls, but not in the amphetamine-treated animals.

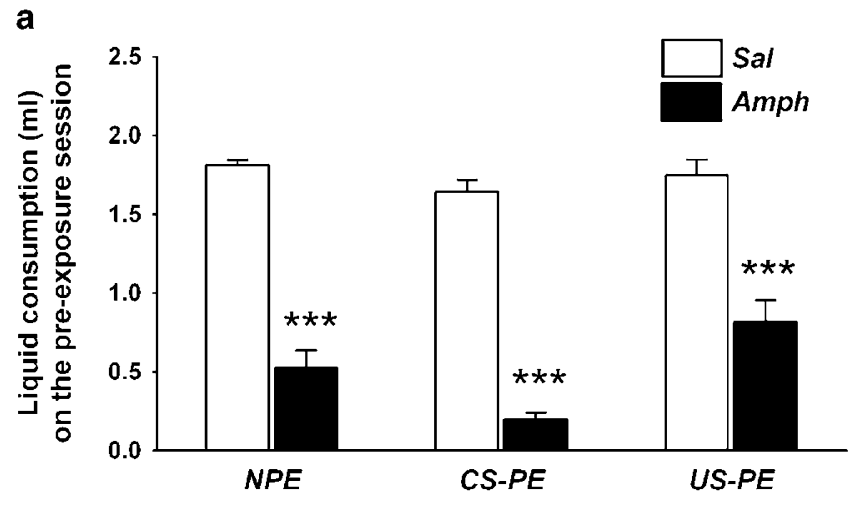

Stimulus Pre-exposure Condition

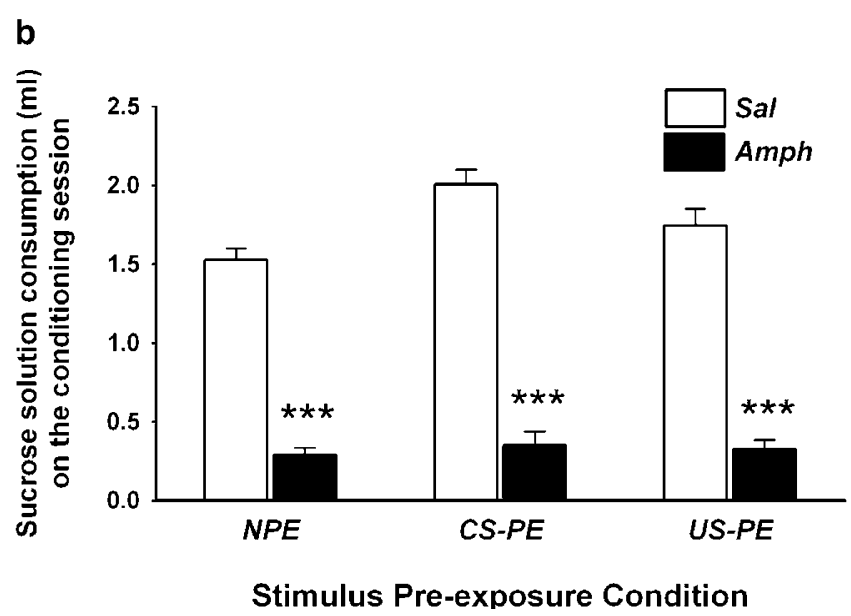

Figure 2 Effects of amphetamine (AMPH) or saline (SAL) on liquid consumption during PE and conditioning session. (a) Liquid consumption (in $\mathrm{ml}$ ) during the PE session. NPE and US-PE animals had access to water, while CS-PE animals were given sucrose solution only, during this session. (b) Consumption of sucrose solution (in $\mathrm{ml}$ ) during the conditioning session when all animals were allowed access to sucrose solution only. All values are means \pm SEM. Symbol **** refers to a significant reduction (Fisher's LSD, $P<0.00$ I) of liquid consumption in each of the amphetamine-treated groups related to their respective saline-treated controls.

These patterns of results led to the emergence of a significant main effect of drug $(\mathrm{F}=463.16, \mathrm{df}=1,60$, $P<0.001)$, of stimulus pre-exposure $(\mathrm{F}=5.46, \mathrm{df}=2,60$, $P<0.01)$, and their interaction $(\mathrm{F}=3.33, \mathrm{df}=2,60, P<0.05)$. Post-hoc comparisons confirmed that Sal/CS-PE mice showed increased sucrose intake compared to the Sal/NPE $(P<0.001)$ or the Sal/US-PE group $(P<0.05)$. There was no difference between Sal/NPE and Sal/US-PE animals.

\section{Test Session}

Conditioned taste aversion was indexed by sucrose consumption as a proportion (in percent) of total liquid consumed during the first drinking period when the animals were confronted with a choice between sucrose solution and water. Reduced aversion to the sucrose solution in the CS-PE and US-PE conditions relative to NPE subjects constitutes the latent inhibition (LI) effect and the USPEE, respectively.

Both LI and the USPEE were clearly evident in the salinetreated animals, while these were completely abolished by 


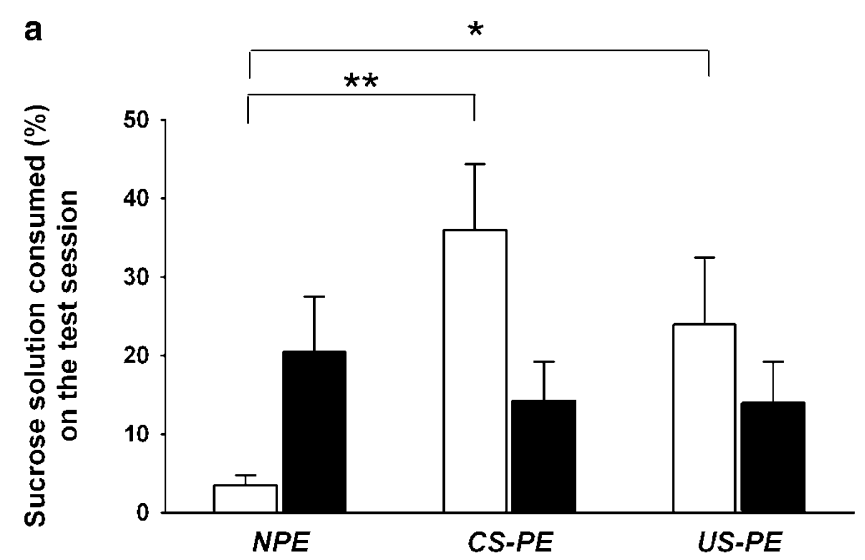

Stimulus Pre-exposure Condition

b

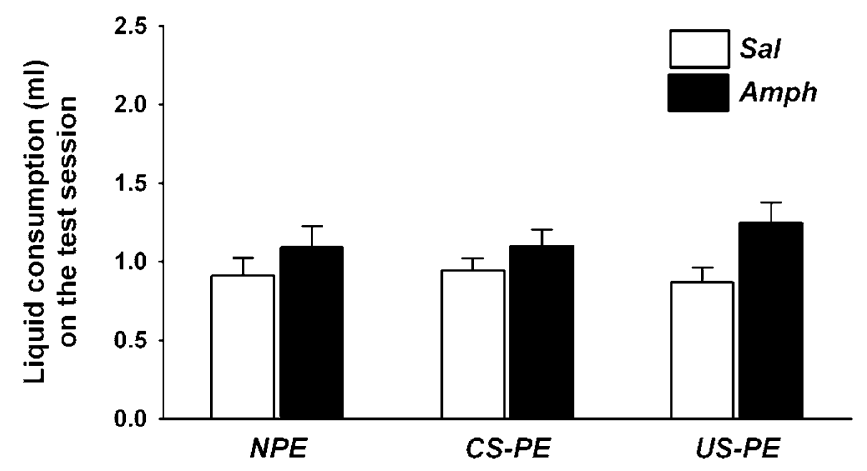

Stimulus Pre-exposure Condition

Figure 3 Effects of amphetamine $(A M P H)$ or saline $(S A L)$ on the expression of the CS- and US-pre-exposure effects and total liquid consumption during the test session. (a) Conditioned taste aversion was indexed by sucrose consumption as a proportion (in percent) of total liquid consumed on the test session when all animals were allowed to freely choose to drink water or sucrose solution. The relative increase in sucrose consumption seen in the Sal/CS-PE and Sal/US-PE animals relative to the Sal/NPE animals constitute the LI effect and the USPEE, respectively. Neither effects was evident in the Amph-treated mice. (b) Total liquid consumption (sucrose solution plus water, in milliliter) during the test session. All values are means $\pm S E M$. Asterisks refers to significant differences $(* P<0.05, * * P<0.01)$ in the indicated contrast between groups based on post-hoc Fisher's LSD comparisons.

amphetamine (Figure 3a). This interpretation is supported by the significant interaction between drug and stimulus pre-exposure $(\mathrm{F}=4.56, \mathrm{df}=2,60, P<0.05)$. Post-hoc comparisons confirmed the presence of LI (Sal/NPE vs Sal/ CS-PE: $P=0.001$ ), and the presence of the USPEE (Sal/NPE vs Sal/US-PE: $P<0.05)$ in the controls. In contrast, no difference was detected in the post-hoc comparisons between different stimulus pre-exposure conditions in the amphetamine-treated mice. Comparison between salineand amphetamine-treated mice within each of the three stimulus pre-exposure conditions revealed a significant difference in the NPE and CS-PE conditions $\left(P^{\prime}\right.$ 's $\left.<0.05\right)$, but not in the US-PE condition.

No other main effect or interaction attained statistical significance.

An additional analysis of the total amount of liquid consumed (sucrose and water) amongst the six experi- mental conditions was conducted to examine any possible effect on drinking behavior per se. This showed that prior amphetamine treatment led to an increase in this measure (Figure 3b), yielding a main effect of drug $(\mathrm{F}=6.71$, $\mathrm{df}=1,60, P<0.05)$. No other main effect or interaction attained statistical significance.

Since amphetamine had exerted an effect on liquid consumption (with consumption reduced on pre-exposure and conditioning phases but enhanced on the test day), we conducted supplementary analyses of covariance (ANCOVAs) to test whether these concomitant effects of amphetamine on drinking behavior as such could account for the drug's effectiveness in abolishing LI and the USPEE. To this end, separate ANCOVAs of the percent sucrose consumption on the test day were conducted with liquid consumption on the pre-exposure day, the conditioning day, or on the test day as the covariate. In all of these analyses, the pattern of results was consistent with the conclusion above. In each case, the interaction between drug and stimulus preexposure remained highly significant, while the covariate term failed to attain statistical significance.

\section{DISCUSSION}

The present study demonstrated for the first time that amphetamine not only disrupts LI, but also abolishes the expression of the USPEE in mice using the CTA paradigm. Following systemic administration of amphetamine $(2.5 \mathrm{mg} /$ $\mathrm{kg}$, i.p.) prior to both the pre-exposure and conditioning phase, the efficacy of either CS or US-pre-exposure to retard subsequent conditioning was rendered completely ineffective.

Amphetamine also exerted a notable effect on liquid consumption on the days of pre-exposure as well as conditioning. This is a known effect of the drug, and has been similarly reported in rats (Russig et al, 2003), although less severely than that observed here. To what extent may these confounding effects undermine the interpretation of the present data? First, the magnitude of LI is a direct function of the number and total time of CS-PE (Schnur and Lubow, 1976; Ayres et al, 1992; De La Casa et al, 1993; De La Casa and Lubow, 1995). Hence, amphetamine might disrupt LI here by reducing sucrose consumption in the Amph/CS$\mathrm{PE}$ mice on the pre-exposure day, thereby undermining the impact of the pre-exposure manipulation in these animals. Second, by attenuating drinking on the conditioning day, amphetamine might diminish the salience of the taste and thus impeded learning of the taste-malaise association and the development of subsequent aversion to the taste in the Amph/NPE animals. Accordingly, the confounding effects of amphetamine treatment on drinking per se had led to an intricate combination of insufficient pre-exposure to the CS and insufficient conditioning, which resulted in a complete abolition of the LI effect. To explain amphetamine's effect on the USPEE, however, only the second line of the argument applies, and hence it would further imply that the abolition of the USPEE solely reflects a lack of tasteconditioned as such in both the Amph/NPE and Amph/ US-PE conditions.

We sought statistical support for the above argument that the concomitant effects of amphetamine on drinking 
behavior as such could account for the abolition of LI and the USPEE by amphetamine in the present experiment, and failed to obtain any support in the additional ANCOVAs conducted. Moreover, we attempted to evaluate within the present data set, whether the above contention has any validity in the saline-treated controls. To this end, we compared the degree of conditioned aversion between highand low-drinking saline-treated controls following a median-split with respect to either liquid consumption on the pre-exposure day, or liquid consumption on the conditioning day. None of these yielded any impression towards diminished LI or the USPEE among the low-drinking controls, relative to the high-drinking controls. Likewise, when we attempted to split amphetamine-treated mice based on liquid consumption on the pre-exposure of conditioning day, the overall pattern of results between high and low drinkers remained similar. Thus, there is little evidence to support the contention that the confounding changes on liquid intake can sufficiently account for our present results.

In agreement with the data reported by Russig et al (2003) in rats, amphetamine enhanced conditioning in the CS-PE mice, while at the same time weakened conditioning in the NPE controls. Thus, the effect of amphetamine on conditioning per se appeared to be bidirectional. The fact that this is equivalently seen in the two species strengthens the possibility that amphetamine acted similarly between rats and mice with respect to its action on LI. The effect of amphetamine on conditioning in the NPE subjects clearly contradicts the hypothesis put forward by Killcross (1994) and Killcross et al (1994), which if anything, predicts that conditioned aversion in the Amph/NPE group should be at a higher (in the absence of any ceiling effect) or comparable (if restricted by a ceiling effect) level relative to the Sal/NPE group.

The efficacy of amphetamine to disrupt LI here extended the previous demonstration of a similar finding in rats with the CTA paradigm of LI (Ellenbroek et al, 1997; Russig et al, 2003). In particular, Russig et al (2003) went on to show that it was necessary to administer amphetamine on both preexposure and conditioning days in order to abolish LI, and that the resultant LI disruption could be antagonized by pretreatment with either haloperidol or clozapine. With the efficacy of amphetamine to disrupt LI now established in the mouse, further characterization of its psychopharmacological profile can proceed, and the parallelism between the two rodent species fully explored.

It has been suggested that amphetamine disrupts LI via interference with CS processing during the pre-exposure phase or the conditioning phase. Several theories have emphasized that the representation of the CS (and its lack of significant consequence) acquired during the pre-exposure phase is directly responsible for the emergence of the LI effect, although the theories differ in the characterization of this psychological process involved, which ranges from selective attention (Mackintosh, 1975a; Pearce and Hall, 1980; Lubow, 1989), mnemonic proactive interference (Bouton, 1993; Kraemer and Spear, 1992), the selective expression of learned behavior (Weiner, 1990; Gray et al, 1991), or the formation of associative links between the preexposed CS and contextual cues (Kruschke, 2001; Escobar et al, 2002; Schmajuk et al, 1996, 1998). Recent evidence derived from lesion studies in rats has further emphasized the view that LI reflects a weakened expression of conditioned responding in the pre-exposed subjects (Jeanblanc et al, 2002). The ability of amphetamine to disrupt LI, and similarly the attenuation of LI in schizophrenia patients, have been interpreted as a disruption of these cognitive or psychological processes.

As mentioned in the Introduction, the USPEE can be, on theoretical ground, understood as a form of Kamin blocking, which asserts that the pre-exposure procedure fosters the formation of an association between the context and the US, which then prevents the formation of the CSUS association when a discrete CS is paired with the US in the same context (Willner, 1978; Riley and Simpson, 2001). However, this view is not substantiated by empirical evidence, since a robust USPEE can be obtained when pre-exposure, conditioning, and test phases are all conducted in the animal's home cage (as in the present study), a context which the subjects would have been extensively preexposed and familiarized to, and thus should have undergone latent inhibition and thereby rendering the critical context-US association unlikely to be established in the first place (Cannon et al, 1975; De Brugada et al, 2003b). Recent evidence has identified instead the injection cues as the stimuli that can be associated with LiCl-induced malaise during US-pre-exposure, and blocks the subsequent association between a novel taste and $\mathrm{LiCl}$-induced gastric malaise during conditioning (De Brugada et al, 2004). The injection cues were more salient and novel compared to other static contextual cues, and would therefore be more readily associated with the subsequent sickness. The suggestion that the injection cues are critical to the demonstration of the USPEE in the CTA paradigm has been demonstrated by the fact that omission of the injection cues alone during conditioning is sufficient to attenuate the USPEE (De Brugada et al, 2004). Hence, the ability of amphetamine to disrupt the USPEE here may be readily anticipated by the drug's known action on Kamin blocking (Crider et al, 1982; Ohad et al, 1987; Jones et al, 1997; O'Tuathaigh et al, 2003).

The apparent importance of injections cues in the CTA learning paradigm highlighted by De Brugada et al (2004) may offer an explanation to the observed reduction of conditioned taste aversion exhibited by Amph/NPE subjects relative to the Sal/NPE controls. The NPE condition in the present study was manipulated on the day of stimulus preexposure: the NPE subjects had received a saline injection, and thereby had been pre-exposed to the injection cues. If this were sufficient to result in latent inhibition of the injection cues, the injection cues would be less effective in competing with the taste of sucrose for associative strength on the next day when ingestion of the novel taste was followed by $\mathrm{LiCl}$ injection. Since LI is diminished by amphetamine treatment, the injection cues would be more capable in competing for associative strength in the Amph/ NPE mice than the Sal/NPE mice; thus leading to the apparent reduction in conditioned aversion to the taste in the former group. An additional NPE control group that does not involve prior experience of the injection cues on the pre-exposure day would be needed to test whether latent inhibition to injection cues could lead to enhanced taste aversion. 
Furthermore, according to the analysis by De Brugada et al (2004), the USPEE demonstrated in the CTA paradigm may represent the combined effects of Kamin blocking (mediated by injection cues-US association) and the USPEE. One approach is to distinguish whether the observed effects of amphetamine on USPEE here is attributed primarily to the drug's effect on Kamin blocking as such is to examine the USPEE in associative learning paradigms in which the contribution of Kamin blocking would be minimal, if any. One possibility is to study the USPEE in active avoidance learning, in which previous exposures to inescapable shock (US pre-exposures) interfere with subsequent avoidance learning. This effect, sometimes also referred to as learned helplessness (within the context of aversive instrumental learning), can readily take place even when pre-exposures to inescapable shock and avoidance learning were conducted in separate apparatus (Seligman and Maier, 1967; Seligman et al, 1975). Thus, if amphetamine can interfere with the USPEE within avoidance learning, it will provide further support to the drug's effect on the USPEE that is beyond its known effect on Kamin blocking. This view is indeed supported by data from our laboratory (unpublished data: Chang, Meyer, Feldon, Yee).

The generality of the parallelism between the psychopharmacology of LI and USPEE highlighted here should also be further examined with other drugs. Current data are lacking because the psychopharmacology of the USPEE has received scant attention. One clear possibility is to test if drugs known to enhance LI and to antagonize amphetamine-induced disruption of LI, such as haloperidol (Weiner and Feldon, 1987), would be similarly efficacious in affecting the expression of the USPEE.

\section{CONCLUSION}

LI, USPEE, and Kamin blocking are all demonstrations of selectivity in associative learning, that is, not all potential CSs have an equivalent capacity to form an effective CS-US association. By preventing the organism from being overloaded with uninformative spurious associations or be burdened with obsolete and nonadaptive associations, such elements of selectivity are fundamental to the adaptive value of learning in general. These phenomena highlighted the associative history of the CSs and USs as a critical determinant of this selectivity. Previous studies in rats and humans have already suggested an important role of central dopamine in the regulation and modulation of selective learning and/or related processes such as acquired selective attention (as reviewed in Moser et al, 2000; Escobar et al, 2002; Weiner, 2003). The present study highlighted the possibility for the first time that the USPEE is likewise under the modulation by dopaminergic system, and thus confirms at least one psychological account of the action of amphetamine (Weiner, 1990).

The present study confirms that systemic amphetamine can disrupt LI in one common mouse strain, and thereby lends credence to the use of the LI procedure to examine the presence of psychotic-like traits in genetic manipulated mice. Although the significance of genetic contribution to behavior and cognition has long been recognized, the development of mouse models in the understanding of neuropsychiatric disorders is a relatively recent event (Gainetdinov et al, 2001; Kilts, 2001; Miyakawa et al, 2003). Considering the continual reliance on the mouse species in the animal modelling of schizophrenia, it is of particular relevance to ask whether fundamental processes linked to schizophrenia-related behavior in rat animal models are also manifested in the murine species. To further examine the neuropharmacological parallelism of LI among human, rats, and mice, the ability of clinical effective antipsychotic drugs to enhance LI or to reverse amphetamine-induced LI deficit ought to be investigated next.

\section{ACKNOWLEDGEMENTS}

The present study was supported by the Swiss Federal Institute of Technology. BK Yee received additional support from the NCCR: Neural Plasticity and Repair, Swiss National Science Foundation. We thank Peter Schmid for his excellent technical assistance. We remain indebted to Jeanne von Arx and Pascal Guela for their care of the animals and to Dr Frank Bootz for his veterinary expertise.

\section{REFERENCES}

Ayres JJB, Philbin D, Cassidy S, Bellino L, Redlinger E (1992). Some parameters of latent inhibition. Learn Motiv 23: 269-287.

Baker AG, Mercier P, Gabel J, Baker PA (1981). Contextual conditioning and the US preexposure effect in conditioned fear. J Exp Psychol Anim Behav Process 7: 109-128.

Baruch I, Hemsley DR, Gray JA (1988). Differential performance of acute and chronic schizophrenics in a latent inhibition task. J Nerv Ment Dis 176: 598-606.

Batson JD, Best PJ (1979). Drug pre-exposure effects in flavoraversion learning: associative interference by conditional environmental stimuli. J Exp Psychol Anim Behav Process 5: 273-283.

Bouton ME (1993). Context, time, and memory retrieval in the interference paradigms of Pavlovian learning. Psych Bull 114: 80-99.

Cannon DS, Berman RF, Baker TB, Atkinson CB (1975). Effect of preconditioning unconditioned stimulus experience on learned taste aversion. J Exp Psychol Anim Behav Process 104: 270-284.

Cole KC, VanTilburg D, Burch-Vernon A, Riccio DC (1996). The importance of context in the US preexposure effect in cta: novel versus latently inhibited contextual stimuli. Learn Motiv 27: 362-374.

Crider A, Solomon PR, McMahon MA (1982). Disruption of selective attention in the rat following chronic D-amphetamine administration: relationship to schizophrenic attention disorder. Biol Psychiatry 17: 351-361.

De Brugada I, Gonzales F, Candido A (2003a). Repeated administration of $\mathrm{LiCl}$ produces an unconditioned stimulus preexposure effect in backward excitatory CTA but not habituation of the unconditioned increment in neophobia. Behav Processes 60: 227-233.

De Brugada I, Gonzales F, Candido A (2003b). The role of injection cues in the associative control of the US preexposure effect in flavour aversion learning. Q J Exp Psych 56B: 241-252.

De Brugada I, Hall G, Symonds M (2004). The US-preexposure effect in lithium-induced flavour-aversion conditioning is a consequence of blocking by injection cues. J Exp Psychol Anim Behav Process 30: 58-66.

De La Casa G, Lubow RE (1995). Latent inhibition in conditioned taste aversion: the roles of stimulus frequency and duration and 
the amount of fluid ingested during preexposure. Neurobiol Learn Mem 64: 125-132.

De La Casa G, Ruiz G, Lubow RE (1993). Amphetamine-produced attenuation of latent inhibition is modulated by the stimulus preexposure duration: implications for schizophrenia. Biol Psychiatry 33: 707-711.

Domjan M, Best MR (1980). Interference with ingestional aversion learning produced by pre-exposure to the unconditioned stimulus: associative and non-associative aspects. Learn Motiv 11: 522-537.

Ellenbroek BA, Knobbout DA, Cools AR (1997). The role of mesolimbic and nigrostriatal dopamine in latent inhibition as measured with the conditioned taste aversion paradigm. Psychopharmacology 129: 112-120.

Escobar M, Oberling P, Miller RR (2002). Associative deficit accounts of disrupted latent inhibition and blocking in schizophrenia. Neurosci Biobehav Rev 26: 203-216.

Gainetdinov RR, Mohn AR, Caron MG (2001). Genetic animal models: focus on schizophrenia. Trends Neurosci 24: 527-533.

Gray JA, Feldon J, Rawlins JNP, Hemsley DR, Smith AD (1991). The neuropsychology of schizophrenia. Behav Brain Sci 14: $1-84$.

Gray JA, Joseph MH, Hemsley DR, Young AMJ, Warburton EC, Boulenguez $\mathrm{P}$ et al (1995). The role of mesolimbic dopaminergic and retrohippocampal afferents to the nucleus accumbens in latent inhibition: implications for schizophrenia. Behav Brain Res 71: 19-31.

Gray NS, Pickering AD, Hemsley DR, Dawling S, Gray JA (1992). Abolition of latent inhibition by a single $5 \mathrm{mg}$ dose of D-amphetamine in man. Psychopharmacology 107: 425-430.

Gray NS, Pilowsky LS, Gray JA, Kerwin RW (1995). Latent inhibition in drug naive schizophrenics: relationship to duration of illness and dopamine D2 binding using SPET. Schizophr Res 17: 95-107.

Jeanblanc J, Hoeltzel A, Louilot A (2002). Dissociation in the involvement of dopaminergic neurons innervating the core and shell subregions of the nucleus accumbens in latent inhibition and affective perception. Neuroscience 111: 315-323.

Jones SH, Hemsley D, Ball S, Serra A (1997). Disruption of the Kamin blocking effect in schizophrenia and in normal subjects following amphetamine. Behav Brain Res 88: 103-114.

Kamin LJ (1969). Predictability, surprise, attention, and conditioning. In: Campbell B, Church $\mathrm{R}$ (eds). Punishment and Aversive Behaviour. Appleton-Century-Crofts: New York.

Killcross AS (1994). What is being measured in latent inhibition experiments: dopamine antagonists influence reinforcement and associative interference, not attention. Behav Pharmacol 5: 49-59.

Killcross AS, Dickinson A, Robbins TW (1994). Amphetamineinduced disruptions of latent inhibition are reinforcer mediated: implications for animal models of schizophrenic attentional dysfunction. Psychopharmacology 115: 185-195.

Kilts CD (2001). The changing roles and targets for animal models of schizophrenia. Biol Psychiatry 50: 845-855.

Kraemer PJ, Spear NE (1992). The effect of nonreinforced stimulus preexposure on the strength of a conditioned taste aversion as a function of retention interval: do latent inhibition and extinction involve a shared process? Anim Learn Behav 20: 1-7.

Kruschke JK (2001). Toward a unified model of attention in associative learning. J Math Psychol 45: 812-863.

Lubow RE (1989). Latent Inhibition and Conditioned Attention Theory. Cambridge University Press: Cambridge UK.

Lubow RE, Moore AU (1959). Latent inhibition: the effect of nonreinforced pre-exposure to the conditional stimulus. J Comp Physiol Psychol 52: 415-419.

Lubow RE, Weiner I, Schnur P (1981). Conditioned attention theory. In: Bower GH (ed). The Psychology of Learning and Motivation. Academic Press: New York.
Mackintosh NJ (1975a). A theory of attention: variations in the associability of stimuli with reinforcement. Psychol Rev 82: 276-298.

Mackintosh NJ (1975b). Blocking of conditioned suppression: role of the first compound trial. J Exp Psychol Anim Behav Process 1: 335-345.

Mackintosh NJ, Turner C (1971). Blocking as a function of novelty of CS and predictability of UCS. Q J Exp Psychol 23: 359-366.

Miyakawa T, Leiter LM, Gerber DJ, Gainetdinov RR, Sotnikova TD, Zeng $\mathrm{H}$ et al (2003). Conditional calcineurin knockout mice exhibit multiple abnormal behaviors related to schizophrenia. Proc Natl Acad Sci 100: 8987-8992.

Moser PC, Hitchcock JM, Lister S, Moran PM (2000). The pharmacology of latent inhibition as an animal model for schizophrenia. Brain Res Rev 33: 275-307.

Ohad D, Lubow RE, Weiner I, Feldon J (1987). The effects of amphetamine on blocking. Psychobiology 15: 137-143.

O'Tuathaigh CM, Salum C, Young AM, Pickering AD, Joseph MH, Moran PM (2003). The effect of amphetamine on Kamin blocking and overshadowing. Behav Pharmacol 14: 315-322.

Pearce JM, Hall G (1980). A model of Pavlovian learning: variations in the effectiveness conditioned but not unconditioned stimuli. Psychol Rev 87: 532-552.

Randich A, LoLordo VM (1979). Associative and nonassociative theories of the UCS preexposure phenomenon: implications for Pavlovian conditioning. Psychol Bull 86: 523-548.

Rescorla RA, Wagner AR (1972). A theory of Pavlovian conditioning: variations in the effectiveness of reinforcement and non-reinforcement. In: Black AH, Prokasy WF (eds). Classical Conditioning, Ii, Current Research and Theory. Appleton-Century-Crofts: New York. pp 64-99.

Riley AL, Simpson GR (2001). The attenuating effects of drug preexposure on taste aversion conditioning: generality, experimental parameters, underlying mechanisms, and implications for drug use and abuse. In: Mowrer RR, Klein SB (eds). Handbook of Contemporary Learning Theories. Lawrence Erlbaum Associates Inc.: Mahawah, NJ.

Russig H, Kovacevic A, Murphy CA, Feldon J (2003). Haloperidol and clozapine antagonise amphetamine-induced disruption of latent inhibition of conditioned taste aversion. Psychopharmacology 170: 263-270.

Schmajuk NA, Buhusi CV, Gray JA (1998). Psychopharmacology of latent inhibition: a neural network approach. Behav Pharmacol 9: 711-730.

Schmajuk NA, Gray JA, Lam YW (1996). Latent inhibition: a neural network approach. J Exp Psychol Anim Behav Process 22: 321-349.

Schnur P, Lubow RE (1976). Latent inhibition: the effects of ITI and CS intensity during pre-exposure. Learn Motiv 7: 540-550.

Seligman MEP, Maier SF (1967). Failure to escape traumatic shock. J Exp Psychol 74: 1-9.

Seligman MEP, Rosellini RA, Kozak MJ (1975). Learned helplessness in the rat: time course, immunization, and reversibility. J Comp Physiol Psychol 88: 542-547.

Solomon PR, Staton DM (1982). Differential effects of microinjections of D-amphetamine into the nucleus accumbens or the caudate putamen on the rat's ability to ignore an irrelevant stimulus. Biol Psychiatry 17: 743-756.

Tarantino LM, Bucan M (2000). Dissection of behaviour and psychiatric disorders using the mouse as a model. Hum $\mathrm{Mol}$ Genet 9: 953-965.

Thornton JC, Dawe S, Lee C, Capstick C, Corr PJ, Cotter P et al (1996). Effects of nicotine and amphetamine on latent inhibition in human subjects. Psychopharmacology 127: 164-173.

Weiner I (2003). The 'two-headed' latent inhibition model schizophrenia: modeling positive and negative symptoms and their treatment. Psychopharmacology 169: 257-297. 
Weiner I (1990). Neural substrates of latent inhibition: the switching model. Psychol Bull 108: 442-461.

Weiner I, Feldon J (1987). Facilitation of latent inhibition by haloperidol in rats. Psychopharmacology 91: 248-253.

Weiner I, Lubow RE, Feldon J (1984). Abolition of the expression but not the acquisition of latent inhibition by chronic amphetamine in rats. Psychopharmacology 83: 194-199.

Weiner I, Lubow RE, Feldon J (1988). Disruption of latent inhibition by acute administration of low doses of amphetamine. Pharmacol Biochem Behav 30: 871-878.

Willner JA (1978). Blocking of a taste aversion by prior pairings of exteroceptive stimuli with illness. Learn Motiv 9: 125-140.

Zorrilla EP (1997). Multiparous species present problems (and possibilities) to developmentalists. Dev Psychobiol 30: 141-150. 